\title{
Effects of Job Stressors, Stress Response, and Sleep Disturbance on Presenteeism in Office Workers
}

This article was published in the following Dove Press journal: Neuropsychiatric Disease and Treatment

Background: Occupational mental health, work environment, sleep health, presenteeism, and loss of work productivity caused by health problems are all public health concerns. Although sleep affects mental health and presenteeism, the associations between sleep disturbance, job stressors, stress responses, and presenteeism have remained unclear. We hypothesized that job stressors affect the presenteeism of office workers through sleep disturbance and analyzed the association among these factors.

Subjects and Methods: In 2017, a cross-sectional survey of adult office workers was performed. A total of 2899 subjects who provided written consent were included in the analysis. The survey collected demographic information, as well as the Work Limitation Questionnaire (WLQ), Pittsburgh Sleep Quality Index (PSQI), and Brief Job Stress Questionnaire (BJSQ). Associations between each of the variables were analyzed by path analysis (covariance structure analysis). This study was approved by the Ethics Committee of Tokyo Medical University.

Results: The path analysis demonstrated that job stressors, psychological and physical stress response (PPSR) in the BJSQ, and sleep disturbance in the PSQI had direct effects on presenteeism in the WLQ. Both job stressors and social support in the BJSQ indirectly affected presenteeism through effects on sleep disturbance and PPSR. Sleep disturbance indirectly affected presenteeism via PPSR. This model accounted for the variation of presenteeism $\left(R^{2}=0.322\right)$.

Conclusion: In the workplace, job stressors and low social support increase presenteeism through psychological and physical stress responses, as well as sleep disturbance. Evaluating and resolving work problems and sleep disturbance would hence be beneficial from the aspects of public health and socioeconomics.

Keywords: job stress, occupational stress, sleep disturbance, presenteeism, work limitation questionnaire, WLQ

\section{Introduction}

In recent years, the concept of presenteeism has aroused public health concern in addition to absenteeism. Presenteeism was proposed in 1955 by Auren as an antonym for absenteeism. ${ }^{1,2}$ Absenteeism represents the absence of workers in workplaces. On the other hand, presenteeism means that workers are attending work, but their ability to perform work is reduced because of physical and mental problems. Presenteeism is known to be the highest among health-associated costs. ${ }^{3}$

In Japan, the number of mood disorder patients in the working generation has continued to increase, ${ }^{4}$ and the number of applications and certifications for occupational
Correspondence: Akiyoshi Shimura

Tel $+8|-3-3342-6|||$

Fax +8I-3-3340-4499

Email sim@tokyo-med.ac.jp
Neuropsychiatric Disease and Treatment 2020:16 1827-1833

1827 
accident compensation for mental disorders has also

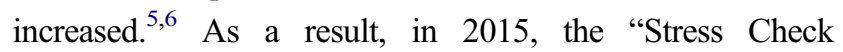
Program", which assesses the situation of stress of employees in workplaces was started. ${ }^{7}$ Workplaces with more than 50 workers are required to implement the Stress Check Program. Previous studies have shown that work demand, control, reward, procedural justice, interactive justice, and support from colleagues and managers are associated with both presenteeism $^{8,9}$ and absenteeism. ${ }^{10}$ We recently reported that job stressors and social support indirectly affect presenteeism through their effects on psychological and physical responses. $^{11}$

On the other hand, factors affecting the physical and mental health of workers are not limited to job stressors. Sleep disturbance may also impair the physical and mental health of workers, leading to depression or anxiety, a reduction in daytime functioning and quality of life, workassociated road accidents, and decreased work outcomes of employees. ${ }^{12-19}$ In addition, job stressors and social support in the workplace affect psychological and physical stress responses through sleep disturbance. ${ }^{20}$ Sleep deprivation is also associated with the loss of productivity and increases in health care costs. ${ }^{21-23}$ There is a possibility that better sleep may improve presenteeism. ${ }^{24}$ Therefore, there may be an association between sleep disturbance and presenteeism, as well as between job stressors and sleep disturbance. However, no studies have analyzed the association among sleep disturbance, job stressors, and presenteeism simultaneously. Based on the above, we hypothesized that job stressors act on productivity loss, ie presenteeism, through their effects on sleep disturbance. In this study, the effects of job stressors and sleep disturbance on presenteeism of adult workers were analyzed by path analysis.

\section{Subjects and Methods Subjects}

In 2017, the following self-administered questionnaires, including the Stress Check Program were distributed to a total of 3314 employees at 17 companies in Tokyo. A total of 2899 (87.5\%) (1837 men and 1062 women; mean age: $36.6 \pm 9.4$ years) who agreed in writing to the academic use of their data were included in the analysis. The questionnaire for demographic information and the questionnaires described in the following section were anonymously surveyed. Participation in this study was entirely voluntary, and nonparticipation did not result in any disadvantage. The collected information was kept anonymous so that the individual could not be identified, and the subjects were informed that the data would not leak to the outside. In accordance with the Declaration of Helsinki, this study was approved by the Ethics Committee of Tokyo Medical University (study approval no.: SH3652).

\section{Questionnaires}

\section{Brief Job Stress Questionnaire (BJSQ)}

The BJSQ is a self-administered stress questionnaire. ${ }^{25}$ "Job stressors (17 items)" measure job stressors, such as job overload, poor physical environment, and interpersonal conflicts. "Psychological and physical stress response (PPSR): (29 items)" measures responses to stress, defined by mental and physical symptoms. "Social support (9 items)" measures the support from bosses, colleagues, family and friends. "Satisfaction of work and life ( 2 items)" was also measured. In all of the subscales, a higher score indicates a higher stress status.

\section{Pittsburgh Sleep Quality Index (PSQI)}

PSQI is a self-administered questionnaire consisting of 18 standardized questions about sleep quality. ${ }^{26,27}$ The questions are all about sleep habits and sleep quality in the previous 1 month. PSQI assesses subjective sleep quality, sleep latency, sleep duration, habitual sleep efficiency, sleep disturbance, use of sleep medication, and daytime dysfunction. In the Japanese version, a global (total) PSQI score of 6 or higher indicates the existence of sleep disturbance, and a higher score indicates a more severe sleep disturbance.

\section{Work Limitation Questionnaire (WLQ; Short Form)} WLQ, including its Japanese version, measures the rate of decline in job performance and work productivity owing to presenteeism. ${ }^{28-30}$ The short form consists of 4 subitems, ie, "time management (2 items)", "physical tasks (2 items)", "mental interpersonal tasks (2 items)", and "output tasks (2 items)". This is a self-administered survey form. From the results of the percentage of time and frequency of failure to perform their duties owing to health problems for the previous 2 weeks, it is possible to calculate the percentage ( $\%$ productivity loss) by which labor productivity has decreased owing to presenteeism relative to the original performance.

\section{Analysis Model}

A path diagram was created based on the hypothesis that job stressors and social support affect presenteeism 
through the PPSR, with sleep disturbance acting as a mediator (see Figure 1).

\section{Statistical Analysis}

Statistical analyses were performed using SPSS Statistics Version 25 and Mplus version 8.0 software (Muthén \& Muthén, Los Angeles, CA, USA). For the path analysis, covariance structure analysis with the robust maximum likelihood estimation method was used. As the model is a saturation model, a goodness-of-fit index was not evaluated. All coefficients of the covariance structure analysis were standardized. For comparison between demographic information and questionnaire data, the Pearson correlation coefficient or the Student's $t$-test was performed.

\section{Results}

\section{Demographic Characteristics of the Subjects and Their Correlation with Loss of Work Productivity}

Table 1 shows the demographic data and data from each questionnaire of the 2899 adult workers. The BJSQ subitems, job stressors, PPSR, and social support were positively correlated with work productivity loss. Higher job stress was associated with worse presenteeism. Furthermore, the PSQI global score and productivity loss score were positively correlated; ie, more severe sleep disturbance was associated with higher presenteeism.

\section{Analysis of Covariance Structural Model}

Figure 1 and Table 2 show the results of the path analysis. Regarding direct effects, significant effects were obtained for all paths except for those from social support to productivity loss (WLQ). Regarding indirect effects, the indirect effects of job stressors on productivity loss through PPSR and sleep disturbance (PSQI) were significant (standardized coefficient: $0.130 ; p<0.001$ and $0.032 ; p<0.001$, respectively). The indirect effects of job stressors on productivity loss through both sleep disturbance and PPSR were also significant (standardized coefficient: $0.033 ; p<0.001$ ). The indirect effects of social support on productivity loss through PPSR and sleep disturbance were significant (standardized coefficient: 0.048; $p<0.001$ and $0.036 ; p<0.001$, respectively). The indirect effects of social support on productivity loss through both sleep disturbance and PPSR were significant (standardized coefficient: $0.037, p<0.001$ ). The indirect effect of sleep disturbance on productivity loss through PPSR was significant (standardized coefficient: $0.167, p<0.001$ ). The indirect

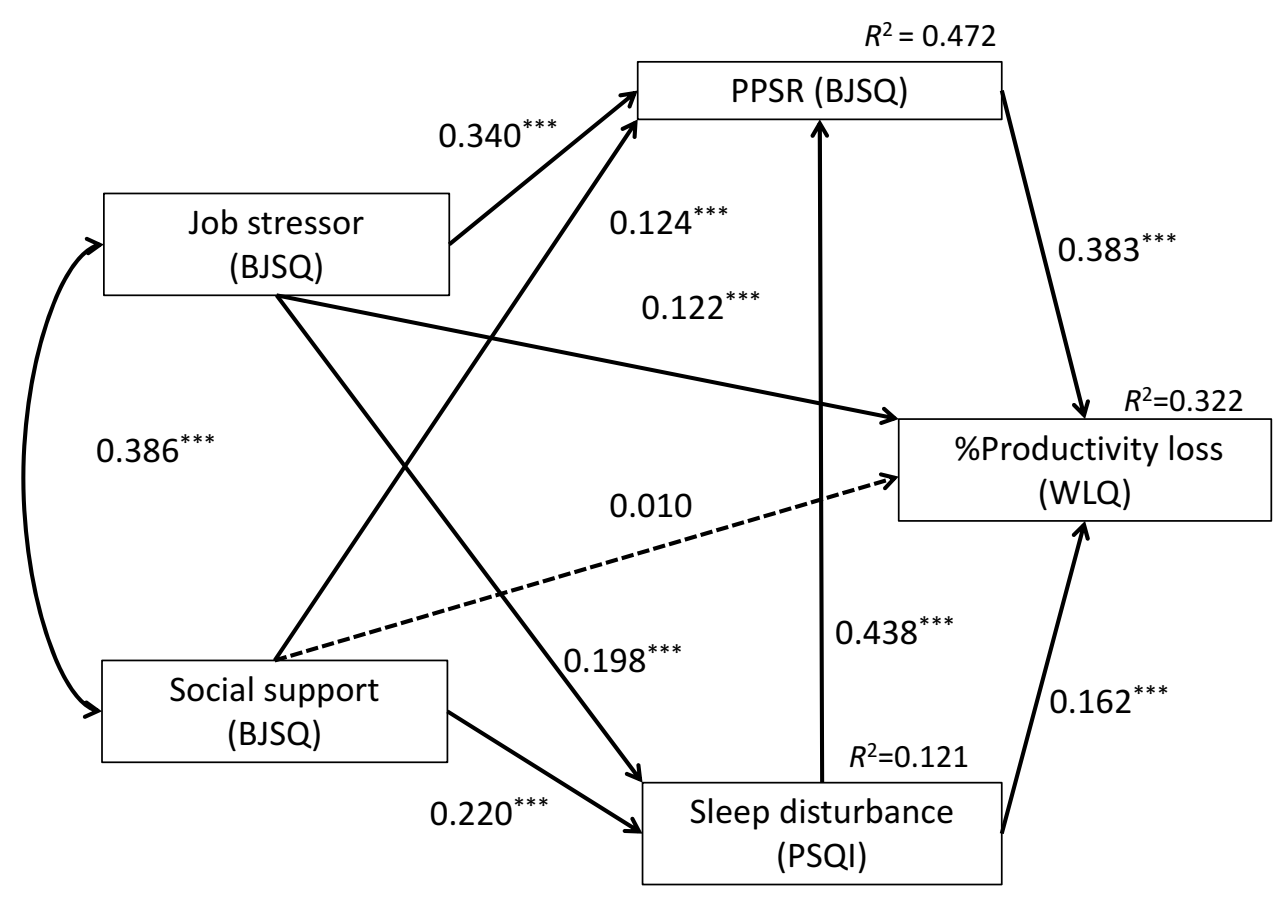

Figure I Results of covariance structure analysis using a path model, with the scores of job stressors, psychological and physical stress response (PPSR), and social support of the Brief Job Stress Questionnaire (BJSQ), the score of the Pittsburgh Sleep Quality Index (PSQI) indicating sleep disturbance, and the score of the percent productivity loss of the Work Limitation Questionnaire (WLQ) indicating presenteeism in 2899 adult workers are shown. Rectangles indicate the observed variables. Arrows with solid lines represent the statistically significant paths, and broken lines show the nonsignificant paths. The numbers beside the arrows show the direct standardized path coefficients. Indirect effects through the variables are explained in the Results section. $* * * p<0.001$. 
Table I Demographic Characteristics and Questionnaire Measures of the Study Subjects and Their Correlation with Percent Productivity Loss of WLQ

\begin{tabular}{|l|l|l|}
\hline $\begin{array}{l}\text { Characteristic or } \\
\text { Measure }\end{array}$ & $\begin{array}{l}\text { Value } \\
\text { (Number or } \\
\text { Mean } \pm \text { SD) }\end{array}$ & $\begin{array}{l}\text { Correlation with \%WLQ } \\
\text { Productivity Loss or Its } \\
\text { Comparison Between Men } \\
\text { and Women }\end{array}$ \\
\hline Sex (men: women) & $1837: 1062$ & $\begin{array}{l}\text { Men: } 5.6 \pm 4.3 \\
\text { Women: } 5.1 \pm 4.1^{*}\end{array}$ \\
\hline Age (years) & $36.6 \pm 9.4$ & $r=-0.11^{* *}$ \\
\hline BJSQ job stressors & $38.9 \pm 6.5$ & $r=0.37^{* *}$ \\
\hline BJSQ PPSR & $56.7 \pm 13.9$ & $r=0.54^{* *}$ \\
\hline BJSQ social support & $19.9 \pm 5.3$ & $r=0.25^{* *}$ \\
\hline PSQI & $6.4 \pm 2.8$ & $r=0.42^{* *}$ \\
\hline $\begin{array}{l}\text { WLQ } \\
\% \text { productivity loss }\end{array}$ & $5.46 \pm 4.20$ & - \\
\hline
\end{tabular}

Notes: Data are presented as means \pm SD or numbers. $r=$ Pearson correlation coefficient; $* p<0.05, * * p<0.01$.

Abbreviations: BJSQ, Brief Job Stress Questionnaire; PPSR, psychological and physical stress response; PSQI, Pittsburgh Sleep Quality Index; WLQ, Work Limitation Questionnaire.

effects of job stressors and social support on PPSR through sleep disturbance were significant $(0.087 ; \mathrm{p}<0.001$ and 0.096 ; $\mathrm{p}<0.001$, respectively). The overall effects on productivity loss were $0.317(p<0.001)$ for job stressors and $0.130(p<$ $0.001)$ for social support. The overall effect of sleep disturbance on productivity loss was $0.330(p<0.001)$, which was greater than the others. The coefficient of determination $\left(R^{2}\right)$ of productivity loss was 0.322 ; ie, this model explains $32.2 \%$ of the variability in presenteeism, productivity loss caused by health problems, of adult workers.

\section{Discussion}

In this study, covariance structure analysis of adult workers showed that job stressors and low social support, as measured by the job Stress Check Program in Japan, have indirect effects on presenteeism, through sleep disturbance and psychological and physical stress responses. Previous studies demonstrated the presence of associations among job stressors, social support, stress responses, and sleep disturbance, $^{20}$ between productivity loss and sleep disturbance, ${ }^{24}$ and among job stressors, stress responses, and productivity loss. ${ }^{8,9,11}$ To date, the role of sleep disturbance in productivity loss had remained unclear. Our study is the first to our knowledge to demonstrate that sleep disturbance is a mediator of the effects of job stressors and social support on presenteeism. These results provide useful suggestions for improving the mental health of workers and solving presenteeism in workplaces.

The effects of job stress and social support on sleep disturbance have been analyzed in previous studies and demonstrated consistent results with this study. These previous studies have suggested a possible solution to improve sleep in the workplace. An anxious temperament and conflicts of job roles are associated with insomnia, and improvement of anxiety and reduction of role conflicts among supervisors and coworkers may reduce the symptoms of insomnia in workers. ${ }^{31}$ Job control and social support show synergistic effects on insomnia, and this may improve sleep disturbance. ${ }^{32}$ A meta-analysis including 5 prospective studies indicated that a high level of job stress, effort-reward imbalance, high demand, heavy workload, and low social support are associated with insomnia. ${ }^{33}$

Sleep disturbance substantially impairs work productivity, performance, and safety. ${ }^{21}$ Sleep deprivation and hypersomnia were also found to be associated with reduced employee productivity. ${ }^{22}$ Employees who follow an optimal lifestyle and get sufficient amounts of sleep have been shown to have minimal loss of productivity. ${ }^{22}$ A strong U-shaped relationship has been reported to exist between hours of sleep and employee health care costs, short-term disability, absenteeism, and presenteeism. ${ }^{23,34}$ These results, including those of the present study, indicate the importance of sleep disturbance in presenteeism.

Consistent with a previous report, ${ }^{11}$ job stressors and social support were found to affect presenteeism through PPSR in this study. Greater support at work from colleagues and employers, and comfortable interpersonal relationships between colleagues, employees, and employers are expected to reduce presenteeism. ${ }^{9}$ Job control, compensation, procedural justice, and interactive justice were shown to reduce presenteeism after 2 years, via a reduction in psychological distress after 1 year. ${ }^{8}$ Job stressors and social support in workplaces affect presenteeism either directly or indirectly by reducing the stress response.

In this study, job stressors and social support had significant indirect effects on presenteeism through sleep disturbance. This means that sleep disturbance should be considered when analyzing the effects of job stressors on presenteeism. In adolescent mental health, the effects of school pressure, physical activity, and mobile use time on psychological symptoms were mediated by sleep. ${ }^{35}$ Furthermore, in our previous study, the effects of job stressors and social support on PPSR were also mediated by sleep. $^{20}$ Sleep problems play a mediating role in the 
Table 2 Standardized Path Coefficients Between the Variables

\begin{tabular}{|c|c|c|c|}
\hline \multicolumn{4}{|c|}{ Direct Effect to } \\
\hline From & Sleep Disturbance (PSQI) & PPSR & \%Productivity Loss (WLQ) \\
\hline $\begin{array}{l}\text { Job stressors } \\
\text { PPSR } \\
\text { Social support } \\
\text { PSQI }\end{array}$ & $\begin{array}{l}0.198 * * * \\
0.220 * * *\end{array}$ & $\begin{array}{l}0.340 * * * \\
0.124 * * * \\
0.438 * * *\end{array}$ & $\begin{array}{l}0.122^{* * *} \\
0.383^{* * *} \\
0.01 \\
0.162 * * *\end{array}$ \\
\hline \multicolumn{4}{|c|}{ Indirect effect to } \\
\hline & Sleep disturbance (PSQI) & PPSR & \%productivity loss (WLQ) \\
\hline Job stressors & $\begin{array}{l}\text { Via PPSR } \\
\text { Via PSQI } \\
\text { Via PSQI +PPSR } \\
\text { Total indirect effect }\end{array}$ & $0.087^{* * *}$ & $\begin{array}{l}0.130 * * * \\
0.032 * * * \\
0.033 * * * \\
0.195 * * *\end{array}$ \\
\hline $\begin{array}{l}\text { Social support } \\
\text { PSQI }\end{array}$ & $\begin{array}{l}\text { Via PPSR } \\
\text { Via PSQI } \\
\text { Via PSQI +PPSR } \\
\text { Total indirect effect } \\
\text { Via PPSR }\end{array}$ & $0.096 * * *$ & $\begin{array}{l}0.048 * * * \\
0.036 * * * \\
0.037 * * * \\
0.120 * * * \\
0.167 * * *\end{array}$ \\
\hline \multicolumn{4}{|l|}{ Total effect to } \\
\hline & Sleep disturbance (PSQI) & PPSR & \%productivity loss (WLQ) \\
\hline $\begin{array}{l}\text { Job stressors } \\
\text { Social support } \\
\text { PSQI }\end{array}$ & & $\begin{array}{l}0.427^{* * *} \\
0.221^{* * *}\end{array}$ & $\begin{array}{l}0.317 * * * \\
0.130 * * * \\
0.330 * * *\end{array}$ \\
\hline
\end{tabular}

Note: $* * * p<0.001$.

Abbreviations: PPSR, psychological and physical stress response; PSQI, Pittsburgh Sleep Quality Index; WLQ, Work Limitations Questionnaire.

association between occupational stress and metabolic syndrome. ${ }^{36}$ Thus, the mediating effects of sleep on various factors of stress are considered to be commonly observed in various situations, such as workplaces and schools.

This study demonstrated the mediating effects of sleep on PPSR and presenteeism. This suggests that not only solving job stress but also solving sleep disturbance may prevent productivity loss owing to health problems in the workplace. Improving job stress is a mission of the business operator, but improving sleep disturbance can be done by each individual worker. For example, improving sleep hygiene is effective for improving sleep disturbance. In some work environments, such as night work, napping before working a night shift is an effective countermeasure to the decreased alertness and performance deterioration associated with night work. ${ }^{37}$ Unfavorable lifestyles, such as using an electronic display in bed or during the 2 hours before bedtime, taking caffeine constantly at night, getting up before dawn, irregular dinner intake times, and a bright living room at night may cause sleep disturbance, and sleep hygiene interventions may promote sleep health. ${ }^{38,39}$ The intervention of lifestyle habits and sleep hygiene may lead to improvements in presenteeism.

This study has some limitations. First, as this study was a cross-sectional survey, we cannot conclude the causal relationship between the factors. Therefore, prospective studies are needed to track the effects of job stressors on sleep and the effects of sleep on presenteeism over time. Second, in this study, self-administered questionnaires were used and the evaluations were subjective. Confirmation of these results using objective analysis methods and a long-term prospective design is necessary for the future. Finally, as our subjects were workers in the city of Tokyo in Japan, it is unclear whether our results can be generalized to different populations in other countries. The work culture and idea of presenteeism in Japan may have influenced the results, and hence different results may be obtained in other countries.

\section{Conclusions}

Job stressors and low social support affect presenteeism through sleep disturbance and psychological and physical 
stress responses. Evaluating and resolving sleep disturbance would hence be beneficial from the aspects of public health and socioeconomics in the workplace.

\section{Author Contributions}

WF and AS designed the study, collected the data, and wrote the protocol. TI supervised the whole of the research project. All authors contributed to data analysis, drafting and revising the article, gave final approval of the version to be published, and agree to be accountable for all aspects of the work.

\section{Funding}

This work was partly supported by a Grant-in-Aid for Scientific Research (no. 16K10194 to T. Inoue and $20 \mathrm{~K} 07955$ to A. Shimura) from the Japanese Ministry of Education, Culture, Sports, Science and Technology, Research and Development Grants for Comprehensive Research for Persons with Disabilities from the Japan Agency for Medical Research and Development (AMED), and a grant from the SENSHIN Medical Research Foundation.

\section{Disclosure}

Akiyoshi Shimura reports personal fees from Meiji Seika Pharma, Yoshitomi Yakuhin, Tanabe Mitsubishi Pharma, and Eisai, outside the submitted work. Jiro Masuya has received personal compensation from Otsuka Pharmaceutical, Eli Lilly, Astellas, and Meiji Yasuda Mental Health Foundation, and grants from Pfizer. Takeshi Inoue has received personal fees from Mochida Pharmaceutical, Takeda Pharmaceutical, Eli Lilly, Janssen Pharmaceutical, MSD, Taisho Toyama Pharmaceutical, Yoshitomiyakuhin, and Daiichi Sankyo; grants from Shionogi, Astellas, Tsumura, and Eisai; and grants and personal fees from Otsuka Pharmaceutical, Dainippon Sumitomo Pharma, Mitsubishi Tanabe Pharma, Kyowa Pharmaceutical Industry, Pfizer, Novartis Pharma, and Meiji Seika Pharma; and is a member of the advisory boards of Pfizer, Novartis Pharma, and Mitsubishi Tanabe Pharma. The other authors declare that they have no actual or potential conflicts of interest associated with this study.

\section{References}

1. Uris A. How to build presenteeism. Pet Refiner. 1955;34:348-359.
2. Smithy DJ. Absenteeism and" presenteeism" in industry. Arch Environ Occup Health. 1970;21(5):670-677. doi:10.1080/000 39896.1970.10667313

3. Collins JJ, Baase CM, Sharda CE, et al. The assessment of chronic health conditions on work performance, absence, and total economic impact for employers. J Occup Environ Med. 2005;47(6):547-557. doi:10.1097/01.jom.0000166864.58664.29

4. Ministry of Health, Labor and Welfare. Patient survey. [Cited Sept 23, 2019]. Available from: https://www.mhlw.go.jp/toukei/list/10-20.html.

5. Yamauchi T, Yoshikawa T, Sasaki T, et al. Cerebrovascular/cardiovascular diseases and mental disorders due to overwork and work-related stress among local public employees in Japan. Ind Health. 2018;56(1):85-91. doi:10.2486/indhealth.2017-0131

6. Yamauchi T, Yoshikawa T, Takamoto M, et al. Overwork-related disorders in Japan: recent trends and development of a national policy to promote preventive measures. Ind Health. 2017;2016-2198.

7. Kawakami N, Tsutsumi A. The stress check program: a new national policy for monitoring and screening psychosocial stress in the workplace in Japan. J Occup Health. 2016;58(1):1-6. doi:10.1539/joh.150001-ER

8. Oshio T, Tsutsumi A, Inoue A, Suzuki T, Miyaki K. The reciprocal relationship between sickness presenteeism and psychological distress in response to job stressors: evidence from a three-wave cohort study. J Occup Health. 2017;17-0178-OA.

9. Yang T, Shen Y-M, Zhu M, et al. Effects of co-worker and supervisor support on job stress and presenteeism in an aging workforce: a structural equation modelling approach. Int $J$ Environ Res Public Health. 2016;13(1):72. doi:10.3390/ijerph13010072

10. Magnavita N, Garbarino S. Is absence related to work stress? A repeated cross-sectional study on a special police force. Am J Ind Med. 2013;56(7):765-775. doi:10.1002/ajim.22155

11. Taya H, Shimura A, Ishibashi Y, Misaki S, Inoue T. Presenteeism associated with job stress. Clin Psychiatry. 2020;in press.

12. Baglioni C, Battagliese G, Feige B, et al. Insomnia as a predictor of depression: a meta-analytic evaluation of longitudinal epidemiological studies. J Affect Disord. 2011;135(1-3):10-19. doi:10.1016/j. jad.2011.01.011

13. Gillin J. Are sleep disturbances risk factors for anxiety, depressive and addictive disorders? Acta Psychiatr Scand. 1998;98(s393):39-43. doi:10.1111/j.1600-0447.1998.tb05965.x

14. Okajima I, Komada Y, Nomura T, Nakashima K, Inoue Y. Insomnia as a risk for depression: a longitudinal epidemiologic study on a Japanese rural cohort. J Clin Psychiatry. 2012;73(3):377-383. doi: $10.4088 / \mathrm{JCP} .10 \mathrm{~m} 06286$

15. Komada Y, Nomura T, Kusumi M, et al. A two-year follow-up study on the symptoms of sleep disturbances/insomnia and their effects on daytime functioning. Sleep Med. 2012;13(9):1115-1121. doi:10.1016/ j.sleep.2012.05.015

16. Kyle SD, Morgan K, Espie CA. Insomnia and health-related quality of life. Sleep Med Rev. 2010;14(1):69-82. doi:10.1016/j.smrv. 2009.07.004

17. Swanson LM, Arnedt JT, Rosekind MR, Belenky G, Balkin TJ, Drake C. Sleep disorders and work performance: findings from the 2008 national sleep foundation sleep in america poll. J Sleep Res. 2011;20(3):487-494. doi:10.1111/j.1365-2869.2010.00890.x

18. Garbarino S, Lanteri P, Durando P, Magnavita N, Sannita WG. Comorbidity, mortality, quality of life and the healthcare/welfare/social costs of disordered sleep: a rapid review. Int J Environ Res Public Health. 2016;13(8):831. doi:10.3390/ijerph13080831

19. Garbarino S, Magnavita N, Guglielmi O, et al. Insomnia is associated with road accidents. Further evidence from a study on truck drivers. PLoS One. 2017;12(10):e0187256. doi:10.1371/journal.pone.018 7256

20. Shimura A, Tanaka T, Misaki S, et al. Assessment of the effect of sleep disturbance and occupational stress on the stress response. Clin Psychiatry. 2018;60(7):783-791. 
21. Rosekind MR, Gregory KB, Mallis MM, Brandt SL, Seal B, Lerner D. The cost of poor sleep: workplace productivity loss and associated costs. J Occup Environ Med. 2010;52(1):91-98. doi:10.1097/JOM.0b013e3181c78c30

22. Katz AS, Pronk NP, Lowry M. The association between optimal lifestyle-related health behaviors and employee productivity. $J$ Occup Environ Med. 2014;56(7):708-713. doi:10.1097/ JOM.0000000000000191

23. Burton WN, Chen C-Y, Schultz AB, Li X. Association between employee sleep with workplace health and economic outcomes. $J$ Occup Environ Med. 2017;59(2):177-183. doi:10.1097/ JOM.0000000000000934

24. Gingerich SB, Seaverson EL, Anderson DR. Association between sleep and productivity loss among 598676 employees from multiple industries. Am J Health Promot. 2018;32(4):1091-1094. doi:10.1177/ 0890117117722517

25. Shimomitsu T. The Final Development of the Brief Job Stress Questionnaire Mainly Used for Assessment of the Individuals. Kato M Ministry of Labour Sponsored Grant for the Prevention of WorkRelated Illness: The 1999 Report. 2000.

26. Doi Y, Minowa M, Uchiyama M, Okawa M. Development of the Japanese version of the Pittsburgh sleep quality index. Jpn J Psychiatr Treat. 1998;13(6):755-763.

27. Buysse DJ, Reynolds CF, Monk TH, Berman SR, Kupfer DJ. The Pittsburgh sleep quality index: a new instrument for psychiatric practice and research. Psychiatry Res. 1989;28(2):193-213. doi:10.1016/0165-1781(89)90047-4

28. Ida H, Nakagawa K, Miura M, Ishikawa K, Yakura N. Development of the work limitations questionnaire Japanese version (WLQ-J): fundamental examination of the reliability and validity of the WLQ-J. Sangyo Eiseigaku Zasshi. 2012;54(3):101. doi:10.1539/sangyoeisei.B11011

29. Lerner D, Amick BC III, Rogers WH, Malspeis S, Bungay K, Cynn D. The work limitations questionnaire. Med Care. 2001;39 (1):72-85. doi:10.1097/00005650-200101000-00009

30. Lerner D, Reed JI, Massarotti E, Wester LM, Burke TA. The work limitations questionnaire's validity and reliability among patients with osteoarthritis. $J$ Clin Epidemiol. 2002;55(2):197-208. doi:10.1016/S0895-4356(01)00424-3
31. Deguchi Y, Iwasaki S, Ishimoto $H$, et al. Relationships between temperaments, occupational stress, and insomnia among Japanese workers. PLoS One. 2017;12(4):e0175346. doi:10.1371/journal. pone.0175346

32. Saijo Y, Chiba S, Yoshioka E, et al. Synergistic interaction between job control and social support at work on depression, burnout, and insomnia among Japanese civil servants. Int Arch Occup Environ Health. 2015;88(2):143-152. doi:10.1007/s00420-014-0945-6

33. Yang B, Wang Y, Cui F, et al. Association between insomnia and job stress: a meta-analysis. Sleep Breath. 2018;22(4):1221-1231. doi:10.1007/s11325-018-1682-y

34. Ishibashi Y, Shimura A. Association between work productivity and sleep health: a cross-sectional study in Japan. Sleep Health. 2020. doi:10.1016/j.sleh.2020.02.016

35. Vandendriessche A, Ghekiere A, Van Cauwenberg J, et al. Does sleep mediate the association between school pressure, physical activity, screen time, and psychological symptoms in early adolescents? A 12-country study. Int J Environ Res Public Health. 2019;16(6):1072. doi:10.3390/ijerph16061072

36. Garbarino S, Magnavita N. Sleep problems are a strong predictor of stress-related metabolic changes in police officers. A prospective study. PLoS One. 2019;14(10):e0224259. doi:10.1371/journal. pone.0224259

37. Garbarino S, Mascialino B, Penco MA, et al. Professional shift-work drivers who adopt prophylactic naps can reduce the risk of car accidents during night work. Sleep. 2004;27(7):1295-1302. doi:10.1093/sleep/27.7.1295

38. Shimura A, Hideo S, Takaesu Y, Nomura R, Komada Y, Inoue T. Comprehensive assessment of the impact of life habits on sleep disturbance, chronotype, and daytime sleepiness among high-school students. Sleep Med. 2018;44:12-18. doi:10.1016/j.sleep.2017.10.011

39. Shimura A, Sugiura K, Inoue M, et al. Which sleep hygiene factors are important? Comprehensive assessment of lifestyle habits and job environment on sleep among office workers. Sleep Health. 2020;(in press). doi:10.1016/j.sleh.2020.02.001
Neuropsychiatric Disease and Treatment

\section{Publish your work in this journal}

Neuropsychiatric Disease and Treatment is an international, peerreviewed journal of clinical therapeutics and pharmacology focusing on concise rapid reporting of clinical or pre-clinical studies on a range of neuropsychiatric and neurological disorders. This journal is indexed on PubMed Central, the 'PsycINFO' database and CAS, and is the official journal of The International Neuropsychiatric Association (INA). The manuscript management system is completely online and includes a very quick and fair peer-review system, which is all easy to use. Visit http://www.dovepress.com/testimonials.php to read real quotes from published authors. 